\title{
Optimization of process factors using the Taguchi method of DOE towards the hydrodeoxygenation of acetic acid
}

\author{
Ahmed Lawal MASHI* and Muhammad Sulaiman RAHAMA \\ Department of Pure and Industrial Chemistry, Umaru Musa Yaradua University, Katsina, Nigeria
}

\begin{abstract}
This paper reports the optimization of process factors using the Taguchi method towards the conversion of acetic acid and ethanol yield during the hydrogenation of acetic acid over $4 \% \mathrm{Pt} / \mathrm{TiO}_{2}$. The acidity of $4 \% \mathrm{Pt} / \mathrm{TiO}{ }_{2}$ was characterized using $\mathrm{NH}_{3}$-Temperature Programmed Desorption analysis $\left(\mathrm{NH}_{3}\right.$-TPD). Afterwards, the effect of temperature on the hydrogenation of acetic acid as an individual feed was investigated. The reaction space explored in the following ranges: temperature $80-200{ }^{\circ} \mathrm{C}$, pressure $10-40 \mathrm{bar}$, time $1-4 \mathrm{~h}$, catalyst $0.1-0.4 \mathrm{~g}$ and stirring speed $400-$ $1000 \mathrm{~min}^{-1}$ using $4 \% \mathrm{Pt} / \mathrm{TiO}_{2}$, was investigated for the optimization study, while the effect of temperature was studied in a temperature range of 145 to $200{ }^{\circ} \mathrm{C}$. $\mathrm{NH}_{3}$-TPD analysis reveals that moderate acidity was suitable for the hydrogenation of acetic acid to ethanol. It was also found that $200{ }^{\circ} \mathrm{C}, 40 \mathrm{bar}, 4 \mathrm{~h}, 0.4 \mathrm{~g}$ and $1000 \mathrm{~min}^{-1}$ for acetic acid conversion, and $160{ }^{\circ} \mathrm{C}, 40 \mathrm{bar}, 4 \mathrm{~h}, 0.4 \mathrm{~g}$ and $1000 \mathrm{~min}^{-1}$ were the optimum conditions for ethanol production. In addition, the selectivity of ethanol was favored at lower temperatures which decreases with increasing temperature.
\end{abstract}

Keywords: hydrodeoxygenation, optimization, Taguchi method.

\section{Introduction}

Biomass, which is a cheap and abundant carbon-based renewable source, has appeared to be a potential alternative feedstock to fossil fuels for the production of fuel grade hydrocarbons [1]. Fast pyrolysis and hydrothermal liquefaction of biomass are the main processes used for the production of bio-oil [2-4]. This makes it a potential alternative for fossil fuels with negligible emissions of nitrogen oxides (NOx) and sulfur dioxide $\left(\mathrm{SO}_{2}\right)$, and carbon neutrality. However, crude bio-oil has limited application as fuel due to high oxygen and aqueous phase content which results in detrimental properties such as high acidity, low heating value, high viscosity and poor miscibility with fossil fuels $[5,6]$. As a result of this, upgrading has become a necessity to enhance its fuel properties. It has been reported in the literature that the complex composition of bio-oil owing to the presence of a large number of hydrocarbons makes it difficult to carry out kinetic studies [5, 7]. However, understanding the contributing reaction routes involving individual bio-oil model compounds would provide details of the overall reaction network. The low polarizability of carboxylic acids makes it difficult to undergo hydrogenation [8]. Catalytic hydrodeoxygenation and zeolite cracking are the most common techniques in bio-oil upgrading. Hydrodeoxygenation (HDO) has been reported to be the preferred upgrading technique compared to zeolite cracking because it produces fuels of higher quality [9]. This process involves the elimination or conversion of oxygenated molecules in the bio-oil under hydrogen pressure using suitable catalyst and temperature to yield products of industrial relevance. However, uneconomical process costs in addition to catalyst deactivation and insufficient understanding of kinetics have been established as the key limitations of hydrodeoxygenation $[6,9]$.

In this study, one-factor-at-a-time (OFAT) and design of experiment (DOE) were considered in order to investigate the optimized factors and their contributions towards the hydrogenation of acetic acid. The application of OFAT by engineers and scientists was considered less effective due to reasons such as time consumption and more experiments, which results in fewer interactions between factors and susceptibility to bias due to time index in experimental errors [10]. Therefore, this makes the DOE more attractive as it offers a predictive knowledge of complex and multivariable processes with a few experimental trials. The application of the different approaches in DOE such as full factorial design, surface response methodology and Taguchi method are relatively similar. However, the Taguchi method is a simpler, cost effective, systematic and comprehensive approach which uses fewer experiments to provide an optimization of complex and multi variable process. Optimization in a Taguchi designed experiment involves reducing the variation in the process by minimizing the effects of uncontrollable factors (noise factors) and keeping the response mean value [11]. In this study, the Taguchi method was used to optimize the controllable reaction factors affecting the hydrogenation of acetic acid.

\footnotetext{
${ }^{*}$ Corresponding author. E-mail address: ahmed.lawal@ umyu.edu.ng (Ahmed Lawal Mashi)
} 


\section{Experimental}

\subsection{Materials}

Acetic acid with $99.5 \%$ purity was purchased from Sigma-Aldrich. Ethanol (purity 99\%), hexane (HPLC grade, $95 \%)$, and ethyl acetate $(99 \%)$ were purchased from Fisher Scientific, UK. $4 \% \mathrm{Pt} / \mathrm{TiO}_{2}$ was chosen from catalyst screening in our previous study [12]. In addition, the method of catalyst preparation has been acknowledged in the same study [12].

\subsection{Experimental setup}

The experimental method used in this study was adopted from our previous work [12]. Figure 1 shows the various reactor components in the experimental setup.

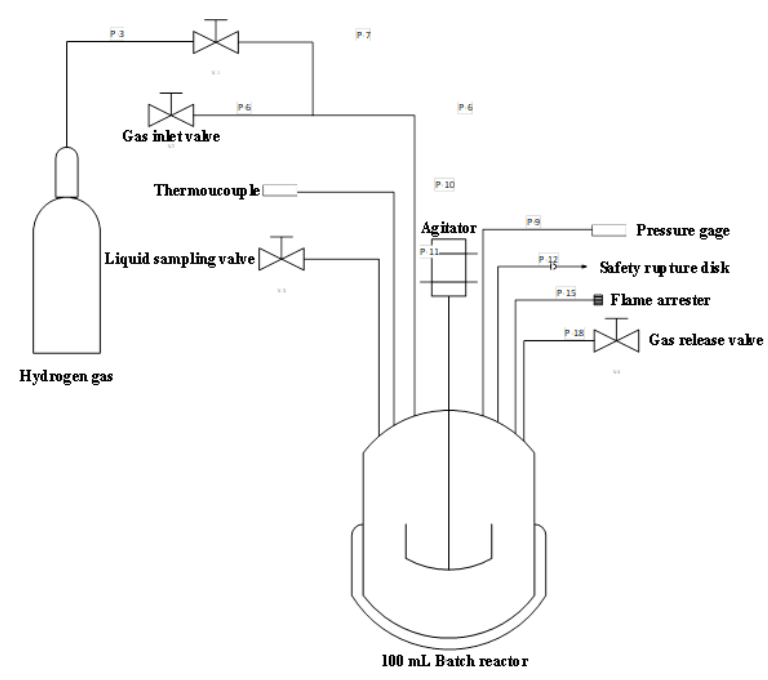

Figure 1. Reactor setup.

\subsection{Catalyst characterization}

$\mathrm{NH}_{3}$-Temperature Programmed Detector ( $\mathrm{NH}_{3}$-TPD) was used to characterize the acidity on $4 \% \mathrm{Pt} / \mathrm{TiO}_{2}$ surface. A ThermoFinnigan TPDRO 1100 equipped with a thermal conductivity detector (TCD) was used to provide information on the acidity of $4 \% \mathrm{Pt} / \mathrm{TiO}_{2}$. During the analysis, $100 \mathrm{mg}$ of $4 \% \mathrm{Pt} / \mathrm{TiO}_{2}$ was placed in the TPDRO cell and then dried at $300{ }^{\circ} \mathrm{C}$ under helium gas for $2 \mathrm{~h}$. Helium was subsequently passed through the sample to reduce the temperature to $50{ }^{\circ} \mathrm{C}$. The temperature was held at $50{ }^{\circ} \mathrm{C}$ and $5 \% \mathrm{NH}_{3} / \mathrm{He}$ at a rate of $20 \mathrm{ml} / \mathrm{min}$ was passed under continuous flow for $1 \mathrm{~h}$ to saturate the samples. Consequently, the weakly physiosorbed $\mathrm{NH}_{3}$ molecules were eliminated by purging the system under the flow of $100 \%$ helium for 1 $\mathrm{h}$. The resulting TCD profiles show the extent of chemisorbed $\mathrm{NH}_{3}$, which were attained by keeping the helium flow constant and increasing the system temperature from $50{ }^{\circ} \mathrm{C}$ to $800^{\circ} \mathrm{C}$ at a rate of $10^{\circ} \mathrm{C} / \mathrm{min}$.

\subsection{Analytical technique}

A mass spectrometer (GC-MS Agilent) was used in identifying formed products from the reactions. The amount of unreacted acetic acid and formed liquid products was carried out using a GC equipped with flame ionization detector (FID) (Shimadzu GC-2010) and a ZB-wax capillary column $(30 \mathrm{~m} \times 0.25 \mathrm{~mm} \times 0.25$ $\mu \mathrm{m})$. Before each analysis, butanol was spiked into the product samples in a ratio of 10:1. Both injector and detector temperatures were kept at $250{ }^{\circ} \mathrm{C}$. A constant pressure mode was initiated to maintain a split flow of 181. The first stage of the GC oven was programmed at $40{ }^{\circ} \mathrm{C}$ and held for 5 minutes. Subsequent heating to 215 ${ }^{\circ} \mathrm{C}$ at $20{ }^{\circ} \mathrm{C} \cdot \mathrm{min}^{-1}$ ramping was carried out before increased heating at a ramp rate of $5{ }^{\circ} \mathrm{C} \cdot \mathrm{min}^{-1}$ to $220{ }^{\circ} \mathrm{C}$ and maintained for $5 \mathrm{~min}$. For reproducibility within negligible error, each sample was injected three times. Equations 1 and 2 were used to calculate the conversion of acetic acid and ethanol selectivity respectively.

$$
\begin{aligned}
& \text { Conversion }(\%)=\frac{\text { (Initial moles of acid-Final moles of acid })}{\text { Initial moles of acid }} \times 100(1) \\
& \text { Selectivity }(\%)=\frac{\text { Moles of acid reacted to desired product }}{\text { Total moles of acid reacted }} \times 100
\end{aligned}
$$

\subsection{Taguchi method of optimization}

An orthogonal array of five controllable factors at four different levels was chosen. The reaction factors considered include reaction temperature, initial hydrogen pressure, catalyst loading, reaction time and stirring speed (Table 1). An array of sixteen experimental runs $\left(\mathrm{L}_{16}\right)$ was generated using design expert software as presented in Table 2, which comprises of five columns that represents the control factors and their respective levels. In addition, the rows represent the sixteen (16) experiments that should be carried out at the given level of each control factor.

Table 1. Selected controllable factors and their levels.

\begin{tabular}{lcccc}
\hline Factors & Level & Level & Level & Level \\
& $\mathbf{1}$ & $\mathbf{2}$ & $\mathbf{3}$ & $\mathbf{4}$ \\
\hline Temperature $\left({ }^{\circ} \mathrm{C}\right)$ & 80 & 120 & 160 & 200 \\
Initial pressure $(\mathrm{bar})$ & 10 & 20 & 30 & 40 \\
Catalyst loading $(\mathrm{g})$ & 0.1 & 0.2 & 0.3 & 0.4 \\
Agitation speed $\left(\mathrm{min}^{-1}\right)$ & 400 & 600 & 800 & 1000 \\
Reaction time $(\mathrm{h})$ & 1 & 2 & 3 & 4 \\
\hline
\end{tabular}

The Taguchi method proposes the signal-to-noise ratio $(\mathrm{S} / \mathrm{N})$ function as a suitable approach in selecting optimum conditions with respect to response variables. Typically, the signal-to-noise ratio is a measure of the desired output signal to the background noise of a response variable [13]. In this study, the larger-thebetter function was chosen based on the objective of achieving a maximum response variable.

$$
\left(\frac{S}{N}\right)=-10 \log \left(\frac{1}{n} \sum_{i=1}^{n} \frac{1}{y_{i}^{2}}\right)
$$

where $n$, is the number of measured value, $y_{i}$ is the measured response value, $y_{i}^{2}$ mean square of measure response value.

The influence of each factor with respect to the hydrogenation of acetic acid was determined by calculating the F-value and P-value using the one-way ANalysis Of VAriance (ANOVA) [14].

$$
\begin{aligned}
& S S_{\text {Total }}=\sum\left(X-\frac{G}{N}\right)^{2} \\
& S S_{\text {within }}=\sum\left(X-\bar{X}_{1}\right) \\
& S S_{\text {between }}=S S_{\text {Total }}-S S_{\text {within }} \\
& D O F_{\text {within }}=N-M \\
& D O F_{\text {between }}=M-1
\end{aligned}
$$




$$
\begin{aligned}
& D O F_{\text {Total }}=D O F_{\text {between }}+D O F_{\text {within }} \\
& \mu S_{\text {between }}=\frac{S S_{\text {between }}}{D O F_{\text {between }}} \\
& \mu S_{\text {within }}=\frac{S S_{\text {within }}}{D O F_{\text {within }}}
\end{aligned}
$$$$
\text { Percentage contribution }(\%)=\frac{\mathrm{SS}_{\text {within }}}{\mathrm{SS}_{\text {Total }}}
$$

where $\mathrm{N}$ is the total number of response values, $\mathrm{M}$ is the number of levels, $\mathrm{G}$ is the sum of all responses at all levels, $X$ is response value and $\bar{X}_{1}$ is the mean of all responses at a particular level.

\section{Results and discussion}

\subsection{Catalyst characterization}

The acidic sites of catalysts are generally categorized into weak, moderate and strong, which corresponds to temperature ranges $\leq 200{ }^{\circ} \mathrm{C}, 200-350{ }^{\circ} \mathrm{C}$ and $\geq 350{ }^{\circ} \mathrm{C}$ respectively [15].

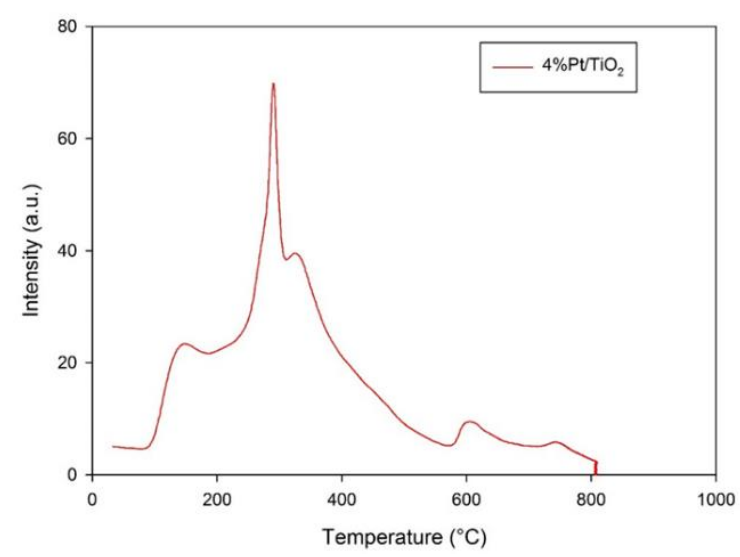

Figure 2. $\mathrm{NH}_{3}-\mathrm{TPD}$ over $4 \% \mathrm{Pt} / \mathrm{TiO}_{2}$
The $\mathrm{NH}_{3}$-TPD profile for $4 \% \mathrm{Pt} / \mathrm{TiO}_{2}$ is shown in Figure 2. The catalyst shows a profile with four desorption peaks in the three different regions of acidic strength. The desorption peaks correspond to temperatures of $140{ }^{\circ} \mathrm{C}, 290{ }^{\circ} \mathrm{C}, 330{ }^{\circ} \mathrm{C}$ and $616^{\circ} \mathrm{C}$. The first peak corresponds to $\mathrm{NH}_{3}$ adsorbed on the weak acid sites. Subsequently, the second and third peaks are classified as moderate acidic sites while the last peak is an indication of strong acidic sites [15, 16]. Accordingly, the number of the acids sites are 0.044 $\mathrm{mmol} \mathrm{g} \mathrm{g}^{-1}, 0.350 \mathrm{mmol} \mathrm{g}^{-1}$ and $0.089 \mathrm{mmol} \mathrm{g}^{-1}$ for the weak, moderate and strong acidic sites respectively, with a total $0.48 \mathrm{mmol} \mathrm{g}^{-1}$ acidic sites on the catalyst.

\subsection{Optimization of process factors}

The influence of reaction factors on ethanol yield over $4 \% \quad \mathrm{Pt} / \mathrm{TiO}_{2}$ was evaluated and their respective contributions quantified. The corresponding $\mathrm{S} / \mathrm{N}$ ratios for experimental runs in the orthogonal array are shown in Table 2. The computation of total $\mathrm{S} / \mathrm{N}$ ratio for each factor at a specific level was carried out by adding the $\mathrm{S} / \mathrm{N}$ ratios for the experiments at the same level. The effect of reaction factors for each level is shown in Figure 3. The upper end of the range of reaction temperature was chosen based on preliminary experiments which shows that at higher temperatures above $200{ }^{\circ} \mathrm{C}$, the conversion of acetic acid remained approximately the same with minimal formation of liquid products while ethanol yield dropped. The S/N profile shows that temperature peaked at $200{ }^{\circ} \mathrm{C}$ and has a strong influence towards the conversion of acetic acid. In addition, the total $\mathrm{S} / \mathrm{N}$ ratios for each factor increased with increasing level, and subsequently reaching maximum at level 4. This observation shows that increased temperatures favors the cleavage of $\mathrm{C}-\mathrm{O}$ bonds through hydrogenolysis towards the formation of ethanol and ethyl acetate with aldehyde as an intermediate.

Table 2. L16 Orthogonal array and corresponding S/N ratio

\begin{tabular}{cccccccccc}
\hline $\begin{array}{c}\text { Exp. } \\
\text { No. }\end{array}$ & $\begin{array}{c}\mathbf{A} \\
\text { Temp. } \\
\left({ }^{\circ} \mathbf{C}\right)\end{array}$ & $\begin{array}{c}\text { Bressure } \\
\text { (bar) }\end{array}$ & $\begin{array}{c}\text { Time } \\
(\mathbf{h})\end{array}$ & $\begin{array}{c}\mathbf{D} \\
\text { Stirring } \\
\left(\mathbf{m i n}^{-1}\right)\end{array}$ & $\begin{array}{c}\mathbf{E} \\
\text { Catalyst } \\
(\mathbf{g})\end{array}$ & $\begin{array}{c}\text { Acetic acid } \\
\text { conversion } \\
(\boldsymbol{\%})\end{array}$ & $\begin{array}{c}\text { S/N } \\
\text { conversion }\end{array}$ & $\begin{array}{c}\text { Ethanol } \\
\text { yield } \\
(\boldsymbol{\%})\end{array}$ & $\begin{array}{c}\text { S/N } \\
\text { yield }\end{array}$ \\
\hline 1 & 1 & 1 & 1 & 1 & 1 & 0.30 & -10.46 & 0.05 & -25.35 \\
2 & 1 & 2 & 2 & 2 & 2 & 1.37 & 2.73 & 0.41 & -7.72 \\
3 & 1 & 3 & 3 & 3 & 3 & 3.79 & 11.57 & 2.08 & 6.38 \\
4 & 1 & 4 & 4 & 4 & 4 & 7.50 & 17.50 & 6.00 & 15.56 \\
5 & 2 & 1 & 2 & 4 & 3 & 29.11 & 29.28 & 16.01 & 24.09 \\
6 & 2 & 2 & 1 & 3 & 4 & 17.61 & 24.92 & 13.91 & 22.87 \\
7 & 2 & 3 & 4 & 2 & 1 & 36.45 & 31.23 & 25.52 & 28.14 \\
8 & 2 & 4 & 3 & 1 & 2 & 35.14 & 30.91 & 29.86 & 29.50 \\
9 & 3 & 1 & 3 & 2 & 4 & 65.07 & 36.27 & 33.19 & 30.42 \\
10 & 3 & 2 & 4 & 1 & 3 & 70.68 & 36.99 & 37.46 & 31.47 \\
11 & 3 & 3 & 1 & 4 & 2 & 50.00 & 33.98 & 32.50 & 30.24 \\
12 & 3 & 4 & 2 & 3 & 1 & 52.26 & 34.36 & 31.88 & 30.07 \\
13 & 4 & 1 & 4 & 3 & 2 & 83.44 & 38.43 & 25.03 & 27.97 \\
14 & 4 & 2 & 3 & 4 & 1 & 81.95 & 38.27 & 28.68 & 29.15 \\
15 & 4 & 3 & 2 & 1 & 4 & 79.30 & 37.99 & 38.06 & 31.61 \\
16 & 4 & 4 & 1 & 2 & 3 & 68.19 & 36.67 & 13.64 & 22.69 \\
\hline
\end{tabular}

Similar to factor $\mathrm{A}$, the total $\mathrm{S} / \mathrm{N}$ ratio of factor $\mathrm{B}$ increased linearly with level and attained maximum at 40 bar. This can be linked to the extent of hydrogen solubility in the reaction mixture which in turn enhances the adsorption of hydrogen and spill over on the surface of $4 \% \mathrm{Pt} / \mathrm{TiO}_{2}$ resulting in attack on the carbonyl species [17]. 
The $\mathrm{S} / \mathrm{N}$ ratio for factor $\mathrm{C}$ increased with reaction time. This observation suggests that extended reaction time strongly favors conversion of acetic acid which corresponds with the maximum conversion achieved at $4 \mathrm{~h}$, thus confirming level 4 to be the optimal reaction time. It is expected that longer time will be required to achieve maximum conversion based on the low polarity of acetic acid and its resistance to hydrogenation [18]. The $\mathrm{S} / \mathrm{N}$ ratio for factor $\mathrm{D}$ increases as stirring speed increases which peaked at level 4. Accordingly, an insignificant increase in $\mathrm{S} / \mathrm{N}$ ratio for stirring speed was observed from level 2 to 4 which confirms negligible degree of external mass transfer effect [12], as shown in Figure 3. The $\mathrm{S} / \mathrm{N}$ ration for factor $\mathrm{E}$ showed that conversion of acetic acid increases with increased catalyst loading. Subsequently, improved catalyst activity with increase in catalyst loading is linked to enhanced number of active sites which are exposed to provide the platform for adsorption of carbonyl carbon that are attacked by spill over hydrogen. As shown in Figures 3 and 4 , the optimum reaction factors can be summarized as $\mathrm{A}_{4}, \mathrm{~B}_{4}, \mathrm{C}_{4}, \mathrm{D}_{4}, \mathrm{E}_{4}$ which corresponds to $200{ }^{\circ} \mathrm{C}, 40 \mathrm{bar}, 4 \mathrm{~h}, 0.4 \mathrm{~g}$ and $1000 \mathrm{~min}^{-1}$ respectively. A validation experiment is essential using the optimum conditions to confirm the highest output response, so long as the optimum conditions are independent of an experimental set in the orthogonal array. Figure 4 shows result from the confirmation experiment which revealed that acetic acid conversion was higher than the highest acetic acid conversion obtained in Experiment 13 of Table 2 which confirms the applicability of the Taguchi technique for the purpose of this study.

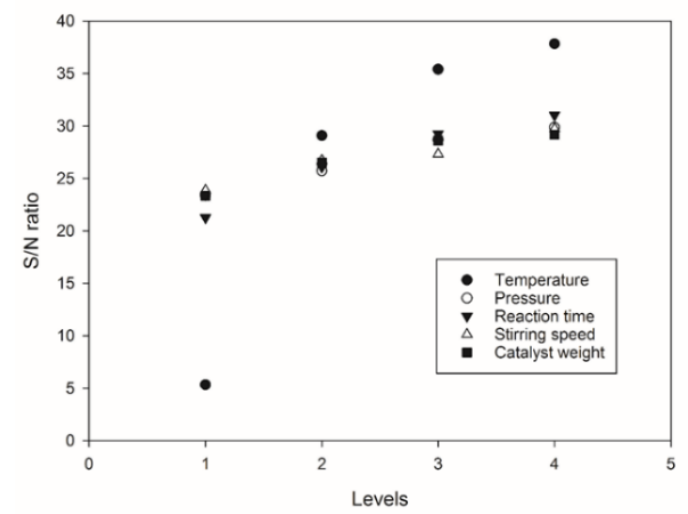

Figure 3. Effect of process factors at each level for conversion of acetic acid

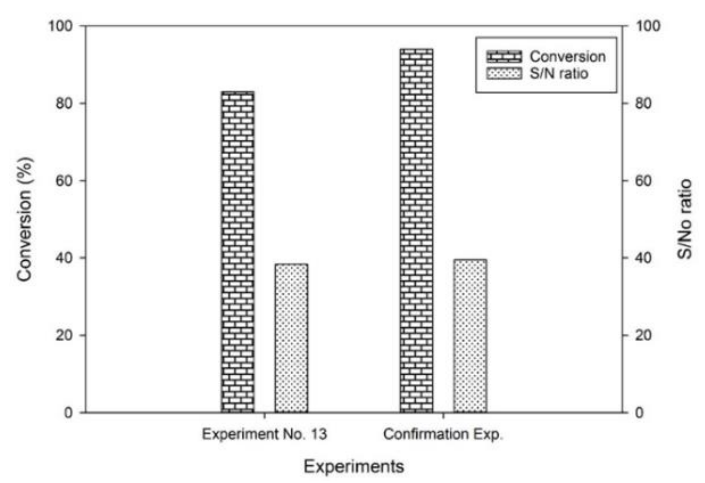

Figure 4. Confirmation experiment under reaction space explored for conversion of acetic acid
Figure 5 shows the ANOVA analysis where the contributory effect of reaction factors was calculated by comparing the individual mean variance $(\mathrm{V})$. It can be observed that temperature had the highest significance on acetic acid conversion while stirring speed had the least. It is worth noting that variance only provides qualitative information in the estimation of the significance of parameters [19-20]. According to the ANOVA results, the contribution of each factor is summarized accordingly: temperature $>$ reaction time $>$ initial $\mathrm{H}_{2}$ pressure > catalyst loading > stirring speed.

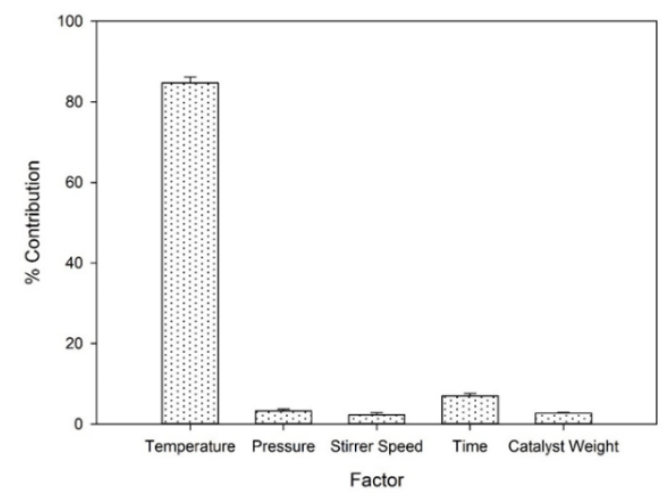

Figure 5. Analysis of variance (ANOVA) for conversion of acetic acid.

To maximize the yield of ethanol, the larger-thebetter function (equation 1) was considered in calculating the $\mathrm{S} / \mathrm{N}$ ratio. Table 2 shows the calculated mean ethanol yield. As shown in Figure 6, each factor except temperature attained maximum $\mathrm{S} / \mathrm{N}$ ratio at level 4. The optimum temperature for ethanol production is $160{ }^{\circ} \mathrm{C}$ which means above $160{ }^{\circ} \mathrm{C}$, there is potential side reaction occurring that favors the production of ethyl acetate. Notably, high pressure and high catalyst weight favors the production of ethanol from the hydrogenation of acetic acid. Figure 7 shows the validation test $\left(160^{\circ} \mathrm{C}, 40 \mathrm{bar}, 4 \mathrm{~h}, 0.4 \mathrm{~g}\right.$ and $1000 \mathrm{~min}^{-}$ ${ }^{1}$ ) in comparison to the highest yield of ethanol as reported in experiment 15 of Table 2. Evidently, the ethanol yield and the $\mathrm{S} / \mathrm{N}$ ratio under the best reaction condition explored is slightly higher than the best reported in Table 2.

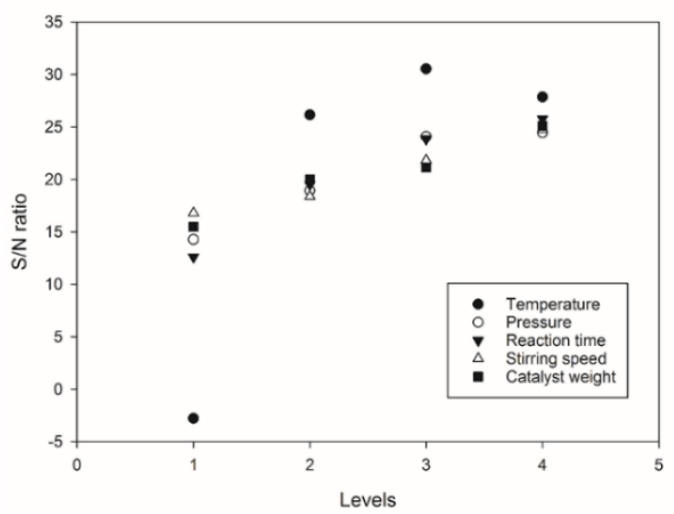

Figure 6. Effect of process factors at each level for yield of ethanol 


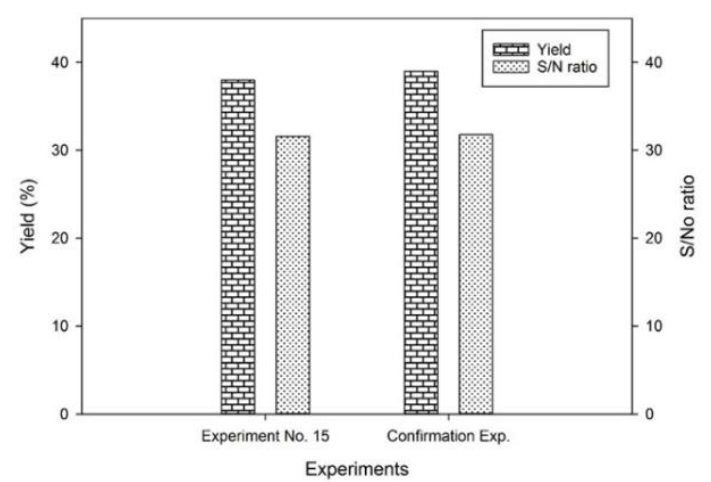

Figure 7. Confirmation experiment under reaction space explored for yield of ethanol

Figure 8 shows the ANOVA analysis for the yield of ethanol as summarized accordingly: temperature > reaction time > initial $\mathrm{H}_{2}$ pressure > catalyst loading > stirring speed. It is worth noting that the ranking order is the same to acetic acid conversion.

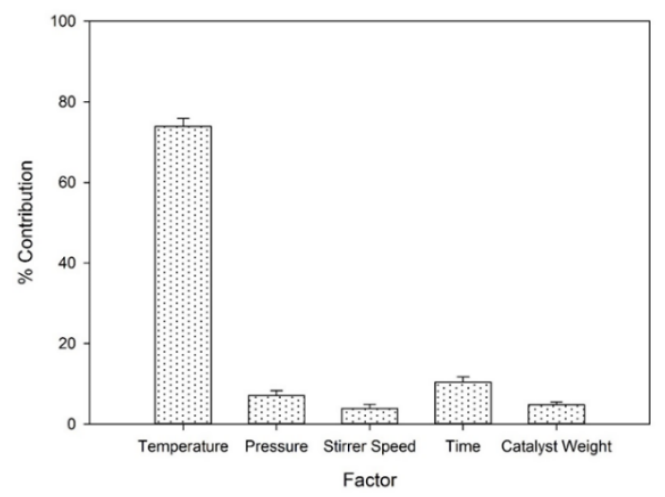

Figure 8. Analysis of variance (ANOVA) for yield of ethanol

\subsection{Effect of temperature on the hydrogenation of} acetic acid

The influence of reaction temperature was investigated towards conversion and product selectivity for the hydrogenation of acetic acid over $4 \% \mathrm{Pt} / \mathrm{TiO}_{2}$ at $2 \mathrm{~h}$ in the range of $145-200{ }^{\circ} \mathrm{C}$.

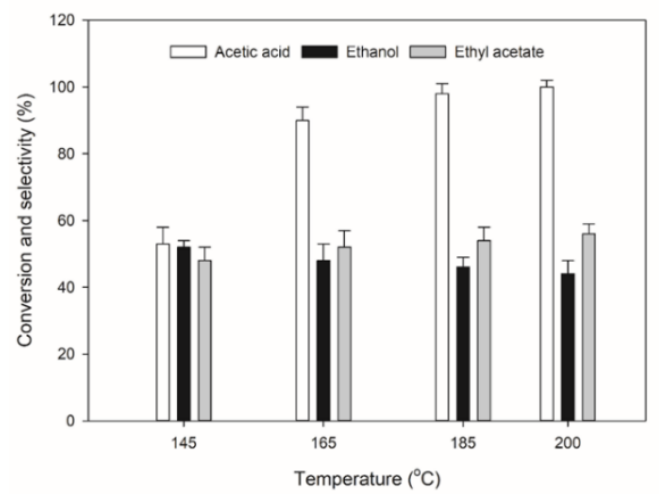

Figure 9. Effect of temperature on the hydrogenation of acetic acid over a) $4 \% \mathrm{Pt} / \mathrm{TiO}_{2}$. Reaction conditions: $0.3 \mathrm{~g}$ of $4 \% \mathrm{Pt} / \mathrm{TiO}_{2} / 4 \% \mathrm{Pt}-4 \% \mathrm{Re} / \mathrm{TiO}_{2}, 0.2 \mathrm{M}$ initial concentration, $\mathrm{H}_{2}$ pressure of $40 \mathrm{bar}, 50 \mathrm{ml}$ of hexane and batch reaction time of $2 \mathrm{~h}$

Figure 9 shows the conversion of acetic acid and selectivities toward ethanol and ethyl acetate. It was observed that formation of liquid products was found to be $\geq 98 \%$ which were mainly ethanol and ethyl acetate. The formation of gaseous products such as $\mathrm{CO}, \mathrm{CO}_{2}$ and $\mathrm{C}_{1}-\mathrm{C}_{4}$ alkanes were linked to the negligible gas formations $(<2 \%)$. Coke formation was not evident and was thus neglected. Figure 9 shows that ethanol selectivity decreased as reaction temperature increased from 145 to $200{ }^{\circ} \mathrm{C}$.

At $145{ }^{\circ} \mathrm{C}$, the conversion of acetic acid was selective towards $53 \%$ ethanol and $48 \%$ ethyl acetate as the primary products (Figure 9). The substantial production of ethyl acetate at low temperature is associated to competitive adsorption of formed ethanol on the catalyst active sites which is evident from adsorption study (See Figure 10). The production of liquid products maintains a high selectivity $\geq 99 \%$ even at $200{ }^{\circ} \mathrm{C}$. This suggests that $4 \% \mathrm{Pt} / \mathrm{TiO}_{2}$ exhibits high acidity which do not favor further hydrogenation and decarboxylation reactions [21]. In addition, high catalyst acidity as reported in Figure 2 favors the protonation of acetic acid which results in the formation ethyl acetate as a by-product. The formation of ethane, methane and $\mathrm{CO}_{2}$ were anticipated to be the negligible gaseous products as reported in earlier studies [16, 22]. It is clear that the conversion of the acetic acid and ethyl acetate selectivity increased while ethanol selectivity decreased with increased reaction temperature from 145 to $200{ }^{\circ} \mathrm{C}$. This suggests that lower temperatures favor the formation of ethanol through enhanced hydrogenation and suppressed esterification.

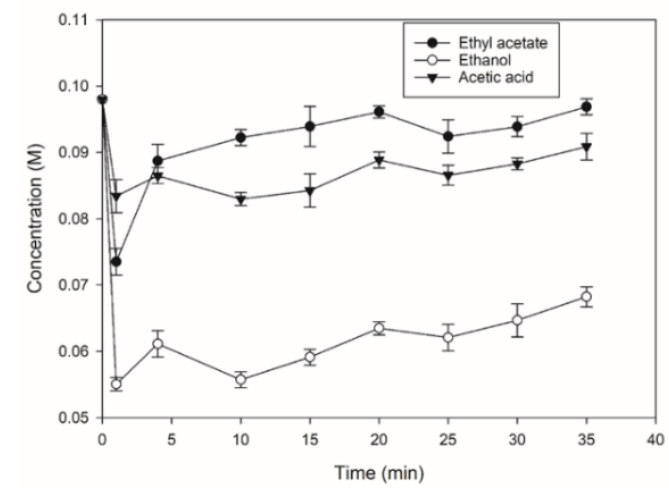

Figure 10. Adsorption study for mixture acetic acid, ethanol and ethyl acetate (experimental conditions: initial concentration, $0.09 \mathrm{M}$; catalyst loading, $0.3 \mathrm{~g}$; and reaction time, 35 min respectively)

\section{Conclusions}

This study revealed the results from Taguchi method of DOE reported for the optimization of reaction conditions towards the maximization of acetic acid conversion and ethanol yield. The optimum conditions for the conversion of acetic acid were found to be 200 ${ }^{\circ} \mathrm{C}, 40$ bar $\mathrm{H}_{2}, 0.4 \mathrm{~g}$ catalyst loading, $1000 \mathrm{~min}^{-1}$, and 4 $\mathrm{h}$ while that of ethanol yield were $160{ }^{\circ} \mathrm{C}, 40$ bar $\mathrm{H}_{2}, 0.4$ g catalyst loading, $1000 \mathrm{~min}^{-1}$, and $4 \mathrm{~h}$. $\mathrm{NH}_{3}$-TPD analysis revealed that moderate acidity on $4 \% \mathrm{Pt} / \mathrm{TiO}_{2}$ favors hydrogenation reaction towards higher ethanol formation. Hydrogenation of acetic acid was found to be more selective toward ethanol than ethyl acetate at lower temperatures. 


\section{Acknowledgment}

The authors gratefully acknowledge the financial support of The Petroleum Technology Development Fund (PTDF), Nigeria.

\section{Conflict of interest}

Authors declare no conflict of interest.

\section{References}

[1]. J. Wang, Z. Luo, J. Zhang, Q. Dang, W. Chen, Reactions of furfural and acetic acid as model compounds for bio-oil upgrading in supercritical ethanol, ICECC (2011) 1587-1592.

[2]. K. Wang, D. Dayton, J. Peters, O. Mante, Reactive catalytic fast pyrolysis of biomass to produce highquality bio-crude, Green Chem. 19 (2017) 32433251.

[3]. R. Shakya, S. Adhikari, R. Mahadevan, E. Hassan, T. Dempster, Catalytic upgrading of bio-oil produced from hydrothermal liquefaction of Nannocloropsis sp., Bioresour. Technol. 252 (2018) 28-36.

[4]. S. Zhang, X. Yang, H. Zhang, C. Chu, K. Zheng, M. Ju, L. Liu, Liquefaction of Biomass and Upgrading of Bio-Oil: A Review, Molecules. 24 (2019) 2250-2279.

[5]. P.M. Mortensen, J.D. Grunwaldt, P.A. Jensen, K.G. Knudsen, A.D. Jensen, A review of catalytic upgrading of bio-oil to engine fuels, Appl. Catal. Gen. 407 (2011) 1-19.

[6]. D.A. Ruddy, J.A. Schaidle, J.R.F. Iii, J. Wang, L. Moens, J.E. Hensley, Recent advances in heterogeneous catalysts for bio-oil upgrading via "ex situ catalytic fast pyrolysis": catalyst development through the study of model compounds, Green Chem. 16 (2014) 454-490.

[7]. Y.H.E. Sheu, R.G. Anthony, E.J. Soltes, Kinetic studies of upgrading pine pyrolytic oil by hydrotreatment, Fuel Process. Technol. 19 (1988) 31-50.

[8]. T. Toyao, S.M.A.H. Siddiki, A.S. Touchy, W. Onodera, K. Kon, Y. Morita, T. Kamachi, K. Yoshizawa, K. Shimizu, $\mathrm{TiO}_{2}$-Supported Re as a general and chemoselective heterogeneous catalyst for hydrogenation of carboxylic acids to alcohols, Chem. Eur. J. 23 (2017) 1001-1006.

[9]. H. Wang, J. Male, Y. Wang, Recent Advances in Hydrotreating of pyrolysis bio-oil and its oxygencontaining model compounds, ACS Catal. 3 (2013) 1047-1070.

[10]. D.D. Frey, F. Engelhardt, E.M. Greitzer, A role for "one-factor-at-a-time" experimentation in parameter design, Res. Eng. Des. 14 (2003) 65-74.

[11]. M. Kowalczyk, Application of Taguchi and Anova methods in selection of process parameters for surface roughness in precision turning of titanium, Adv. Manuf. Sci. Technol. 38 (2014) 21-35.

[12]. A.M. Lawal, A. Hart, H. Daly, C. Hardacre, J. Wood, Kinetics of hydrogenation of acetic acid over supported platinum catalyst, Energy Fuels 33 (2019) 5551-5560.

[13]. I.N. Tansel, S. Gülmez, M. Demetgul, Ş. Aykut, Taguchi Method-GONNS integration: Complete procedure covering from experimental design to complex optimization, Expert Syst. Appl. 38 (2011) 4780-4789.

[14]. S. Athreya, D.Y.D. Venkatesh, Application of Taguchi method for optimization of process parameters in improving the surface roughness of lathe facing operation, IRJES 1 (2012) 13-19.

[15]. V. Sundaramurthy, A.K. Dalai, J. Adjaye, The effect of phosphorus on hydrotreating property of $\mathrm{NiMo} / \gamma-\mathrm{Al}_{2} \mathrm{O}_{3}$ nitride catalyst, Appl. Catal. Gen. 335 (2008) 204-210.

[16]. Z. He, X. Wang, Required catalytic properties for alkane production from carboxylic acids: Hydrodeoxygenation of acetic acid, J. Energy Chem. 22 (2013) 883-894.

[17]. F. Zaera, The surface chemistry of metal-based hydrogenation catalysis, ACS Catal. 7 (2017) 4947-4967.

[18]. J. Pritchard, G.A. Filonenko, R. Putten, E.J.M. Hensen, E.A. Pidko, Heterogeneous and homogeneous catalysis for the hydrogenation of carboxylic acid derivatives: history, advances and future directions, Chem. Soc. Rev. 44 (2015) 3808-3833.

[19]. S. Srivastava, G.C. Jadeja, J. Parikh, Coppercobalt catalyzed liquid phase hydrogenation of furfural to 2-methylfuran: An optimization, kinetics and reaction mechanism study, Chem. Eng. Res. Des. 132 (2018) 313-324.

[20]. Y.Ş. Yildiz, Optimization of Bomaplex Red CR-L dye removal from aqueous solution by electrocoagulation using aluminum electrodes, J. Hazard. Mater. 153 (2008) 194-200.

[21]. P.K. Rakshit, R.K. Voolapalli, S. Upadhyayula, Acetic acid hydrogenation to ethanol over supported Pt-Sn catalyst: Effect of Bronsted acidity on product selectivity, Mol. Catal. 448 (2018) 78-90.

[22]. H. Wan, R.V. Chaudhari, B. Subramaniam, Aqueous Phase Hydrogenation of Acetic Acid and Its Promotional Effect on $p$-cresol hydrodeoxygenation, Energy Fuels 27 (2013) 487493.

Received: 02.04.2020

Received in revised form: 22.05.2020

Accepted: 22.05.2020 